\title{
Histochemical and ultrastructural analysis of pathology and cell responses in gills of channel catfish affected with proliferative gill disease
}

\author{
J. Lovy ${ }^{1, *}$, A. E. Goodwin ${ }^{2}$, D. J. Speare ${ }^{3}$, D. W. Wadowska ${ }^{4}$, G. M. Wright ${ }^{5}$ \\ ${ }^{1}$ Fisheries and Oceans Canada, Pacific Biological Station, Aquatic Animal Health Unit, 3190 Hammond Bay Road, Nanaimo, \\ British Columbia V9T 6N7, Canada \\ ${ }^{2}$ University of Arkansas at Pine Bluff, Aquaculture/Fisheries Center, Pine Bluff, Arkansas 71601, USA \\ ${ }^{3}$ Department of Pathology and Microbiology, ${ }^{4}$ Department of Graduate Studies and Research, \\ and ${ }^{5}$ Department of Biomedical Sciences, Atlantic Veterinary College, University of Prince Edward Island, Charlottetown, \\ Prince Edward Island C1A 4P3, Canada
}

\begin{abstract}
Pond-reared channel catfish Ictalurus punctatus with proliferative gill disease (PGD), caused by the myxozoan parasite Henneguya spp., were examined with light and transmission electron microscopy to better characterize the inflammatory response during infection. The early stages of disease are characterized by the destruction of collagen in the matrix of the gill filament cartilage causing weakness and breaks within the gill filaments. These early lesions lacked a notable inflammatory response around the disrupted cartilage, a chondrocyte response was not apparent, and the parasite was not present, suggesting that the cartilage breaks occur prior to inflammation and arrival of the parasite in the gill. In later lesions, a significant inflammatory response was generated in areas of disrupted cartilage, and the inflammatory infiltrate was composed of a mixed population of granulocytes including neutrophils and cells that resembled eosinophils. The majority of eosinophil-like cells demonstrated evidence of degranulation. Trophozoites of Henneguya spp. were surrounded by a uniform population of cells believed to be neutrophils. The granulocytes were infiltrated within the dense collagen layer of the gill filament cartilage and often appeared within chondrocyte lacunae in place of the chondrocyte. The gill lamellae adjacent to the lesions were fused and contained an inflammatory infiltrate containing granulocytes and cells with pericentriolar granules that resembled previous descriptions of Langerhans-like cells. These cells were abundant within damaged lamellar epithelium, but were only rarely found within the gill filament. Lesions that appeared to be recovering lacked the dense collagenous layer around the cartilage and contained hyperplastic and hypertrophic chondrocytes that formed a callus. Other chondrocytes in the lesions had ultrastructural features indicative of cell death.
\end{abstract}

KEY WORDS: Channel catfish · Proliferative gill disease · Inflammation · Henneguya · Collagen · Pathology · Ultrastructure

Resale or republication not permitted without written consent of the publisher

\section{INTRODUCTION}

Fish gills serve as an entry point for pathogens because of their direct contact with the environment and because physiological constraints require only a fragile barrier between the environment and the circulatory system. Immune mechanisms are required in the gill to reduce the likelihood of successful invasion by pathogens. When rainbow trout Oncorhynchus mykiss are infected with Renibacterium salmoninarum, the gills produce a quick and prolonged nitric oxide synthase response (Campos-Perez et al. 2000). The gill itself also contains lymphoid tissue rich in T cells (Haugarvoll et al. 2008) and CD4 receptors that are necessary for cell-mediated immunity (Buonocore et al. 2008). Gill disease models are helpful in determining 
how gills respond to disease with the initial inflammatory response generated during an infection, which is critical for the development of adaptive immunity. In salmonids infected with the gill microsporidian Loma salmonae, acute and chronic inflammatory responses are observed in the gill, and characterization of the inflammatory infiltrate led to the discovery of a cell type that resembles mammalian Langerhans cells (Lovy et al. 2006). It is hypothesized that these cells are resident in secondary lymphoid tissues, particularly in the spleen, and are recruited systemically to initiate adaptive immune responses during inflammatory insults (Lovy et al. 2006, 2008, 2009).

An inflammatory process is associated with proliferative gill disease (PGD) that affects pond-reared channel catfish Ictalurus punctatus in the southern USA and can lead to mortality rates exceeding $50 \%$ (Bowser \& Conroy 1985). In PGD, the gills of channel catfish are infected by the actinosporean stage of the myxozoan parasite Henneguya ictaluri, which develops within the benthic oligochete Dero digitata (Styer et al. 1991, Pote et al. 2000). Infection with the parasite occurs through multiple portals including the skin, gills and gastric mucosa (Belem \& Pote 2001). The parasite first induces severe congestion and hemorrhaging in the gill, which develops into epithelial hyperplasia, inflammation and lytic cartilage lesions (Griffin et al. 2010). The presence of broken gill filament cartilage in pondreared channel catfish is pathoneumonic for PGD, but histology and real-time PCR are often used as confirmatory tests (Griffin et al. 2008, Pote et al. 2010). The severe inflammatory response elicited during PGD is believed to cause lysis of the cartilage leading to breaks within the cartilage (MacMillan et al. 1989). The goals of the present study are to examine the pathology associated with PGD in the gills of channel catfish by means of light microscopy and transmission electron microscopy in order to characterize the host cells present in the inflammatory response and to characterize the gill microenvironment within lesions.

\section{MATERIALS AND METHODS}

Five 10 to $15 \mathrm{~cm}$ channel catfish were collected from a commercial catfish fingerling production pond on a fish farm in Arkansas, USA, during a single sample period during the month of May. The fish in the pond were swimming in the proximity of the aerators and displaying signs of oxygen deprivation. Grossly, the gill filaments of the affected fish appeared thickened and many were bent. Wet mount preparations of gills demonstrated breaks in the gill filament cartilage. These behavioral and clinical signs were consistent with a severe, active PGD.
Light microscopy. Gill tissue was fixed in formalin for at least $24 \mathrm{~h}$, dehydrated through a series of ethanols, cleared in xylene and embedded in paraffin wax. Serial sections, $5 \mu \mathrm{m}$ thick, were cut and mounted on multiple glass slides. The tissues were stained with either hematoxylin and eosin (H\&E), Alcian blue, Safranin O, Masson's trichrome or periodic acid-Schiff (PAS). Slides were viewed and photographed with a microscope (Axioplan 2, Zeiss) equipped with a high resolution digital camera (AxioCam) with Axiovision software v. 4.5.0.0 (Carl Zeiss Canada).

High resolution light microscopy and transmission electron microscopy. Fish gills were fixed in $2 \%$ glutaraldehyde in $0.1 \mathrm{M}$ phosphate buffer, $\mathrm{pH} 7.2$, packaged with ice packs and sent to the Atlantic Veterinary College (AVC), Charlottetown, Prince Edward Island. Upon receipt the gill tissue was cut into smaller pieces and placed into fresh $2 \%$ buffered glutaraldehyde and kept at $4^{\circ} \mathrm{C}$ overnight. The tissue was then washed in $0.1 \mathrm{M}$ phosphate buffer and transferred to $1 \%$ osmium tetroxide in phosphate buffer for $1 \mathrm{~h}$ at room temperature. Dehydration through a series of ethanol grades to propylene oxide immediately followed osmium fixation. The tissue was then infiltrated with a mixture of Spurr's resin and propylene oxide in a ratio of $1: 1,3: 1$, and lastly in pure Spurr's resin for $24 \mathrm{~h}$ each. The tissue was embedded in pure Spurr's resin (Canemco) at $60^{\circ} \mathrm{C}$ for $24 \mathrm{~h}$. Semi-thin sections $(0.5 \mu \mathrm{m})$ were cut from 5 blocks of tissue from each infected fish. The sections were stained with $1 \%$ toluidine blue in $1 \%$ sodium tetraborate solution and viewed with the light microscope. All samples that contained cartilage lesions and an inflammatory response were re-cut to generate ultra-thin sections $(90 \mathrm{~nm})$. The ultra-thin sections were retrieved onto copper super grids (200 mesh) and stained with uranyl acetate and Sato's lead stain. The sections were examined with a transmission electron microscope (Hitachi H7500, Nissei-Sangyo) operated at $80 \mathrm{kV}$ and imaged with a side mount digital camera (AMT XR40, Advance Microscopy) by means of the Image Capture Engine Software v. 600.149 .

\section{RESULTS}

\section{Light microscopy}

Staining with H\&E and toluidine blue demonstrated both the territorial matrix, rich in glycosaminoglycans (GAGs), and the interterritorial matrix (collagenous component) of the gill cartilage. With H\&E staining the collagen was eosinophilic and the territorial matrix was basophilic. The toluidine blue showed less specific 
staining in which both components were blue. The Masson's trichrome stain clearly identified the collagenous component of the cartilage. Both Safranin $O$ and Alcian blue staining demonstrated the GAG-rich areas. The normal gill filament cartilage within the sample contained varying numbers of chondrocytes surrounded by a territorial matrix made up of GAGs and a fibrous collagenous layer surrounding the territorial matrix. Two different morphological types of normal gill filament cartilage were observed. One type contained predominantly collagen with only a few rounded chondrocytes, while the second contained an organized network of cuboidal chondrocytes surrounded by collagen. In some instances the more cellular cartilage was found closer to the gill filament tips, whereas the less cellular form was found closer to the base of the filaments.

In gills infected with Henneguya, trophozoites were surrounded by mononuclear host inflammatory cells (Fig. 1A). The mononuclear cells had a PAS-positive granular cytoplasm. Trophozoites were not observed in all areas of chondrocyte lesions and cartilage breaks. Several types of lesions were observed affecting the gill filament cartilage. One type of lesion had gill filament cartilage with incontinuities in the extracellular matrix resulting in breaks in the cartilage (Fig. 1B,C). These lesions had a minimal inflammatory infiltrate and parasites were not present (Fig. 1B,C, arrows). Other lesions with similar cartilage breaks and missing the extracellular matrix had a noticeable inflammatory infiltrate with parasite trophozoites (Fig. 1D). In lesions with a severe inflammatory infiltrate and parasite trophozoites there was a complete loss of the gill filament cartilage (Fig. 1C, arrowhead). Epithelial hyperplasia and lamellar fusion were common adjacent to the damaged gill filament cartilage (Fig. 1C). Another type of lesion was the gill filament cartilage missing the surrounding dense collagenous component and containing hyperplastic and hypertrophic chondrocytes adjacent to the missing collagen (Fig. 1E-G). In these lesions containing the hypertrophic chondrocytes the parasite was not present and the inflammatory response was mild or absent. In both toluidine blue-stained and Masson's trichrome-stained sections the deep blue staining of the normal collagenous matrix making up the cartilage was missing in the areas of chondrocyte hypertrophy (Fig. 1E,F). The toluidine blue-stained lesions demonstrated a metachromatic staining within the territorial matrix around the hypertrophic chondrocytes (Fig 1E). In H\&E-stained sections the eosinophilic-staining collagen was missing in the areas of broken cartilage with hyperplastic and hypertrophic chondrocytes, while the unaffected areas still had the eosinophilic collagenous matrix intact (Fig 1G).

\section{Transmission electron microscopy}

Ultrastructural characterization of the host cells within inflammatory lesions revealed a homogenous population of mononuclear cells directly surrounding the parasite (Fig. 2A). These cells contained 2 types of granules, elongated granules with material in a fibrillar arrangement (Fig. 2B, arrows) and small pleomorphic granules containing electron-dense amorphous material (Fig. 2B, arrowheads). These granules are characteristic for fish neutrophils. Inflammation in the gills became locally diffuse in areas not directly surrounding the parasite and extended from the gill filament to the adjacent lamellar epithelium. The inflammatory infiltrate contained a mixed population of leukocytes including cells that resembled neutrophils, and other granulocytes with large intact granules similar in morphology to mast cells (also known as eosinophilic granular cells). Other cells with abundant relatively small granules with variably electron-dense material were observed (Fig. 2C). A majority of these cells showed evidence of degranulation, in which this central component of the oval or spherical granules was degranulated (Fig. 2D,E). The majority of inflammatory cells were adjacent to the collagen layer of the filament cartilage. The inflammatory cells had pseudopods extending into the collagen and cells were observed within the dense collagenous layer (Fig. 2F). The inflammatory cells invaded the interterritorial matrix and often infiltrated the chondrocyte lacunae among other granulocytes replacing the chondrocytes.

Previously described fish cells with unique pericentriolar granules that resemble Langerhans cells were common within the inflammatory infiltrate. These cells were found within the fused lamellar epithelium (Fig. 3A) but only rarely occurred within the gill filament. The cells characteristically had a network of granules, often containing electron-dense deposits, localized around the centrisome (Fig. 3B,D). The luminal material within the granules was of variable electron density and electron-dense bodies were frequently observed within the granules (Fig. 3B-D).

Ultrastructural differences were observed between normal gill cartilage and the cartilage associated with PGD lesions. Two types of normal gill filament cartilage were observed: mature predominantly acellular cartilage (Fig. 4A,B) and highly cellular cartilage (Fig. 4C). In the mature predominantly acellular gill filament cartilage the fibrous component was made up mostly of collagen and electron-dense material which is likely the proteoglycan component of the territorial matrix (Fig. 4A,B). The chondrocytes were embedded within the thick fibrous component. The chondrocytes were rounded, relatively small, devoid of organelles, and nuclei were euchromatic with peripheral heterochromatin (Fig. 4A,B). In the highly cellular filament cartilage the chondrocytes 

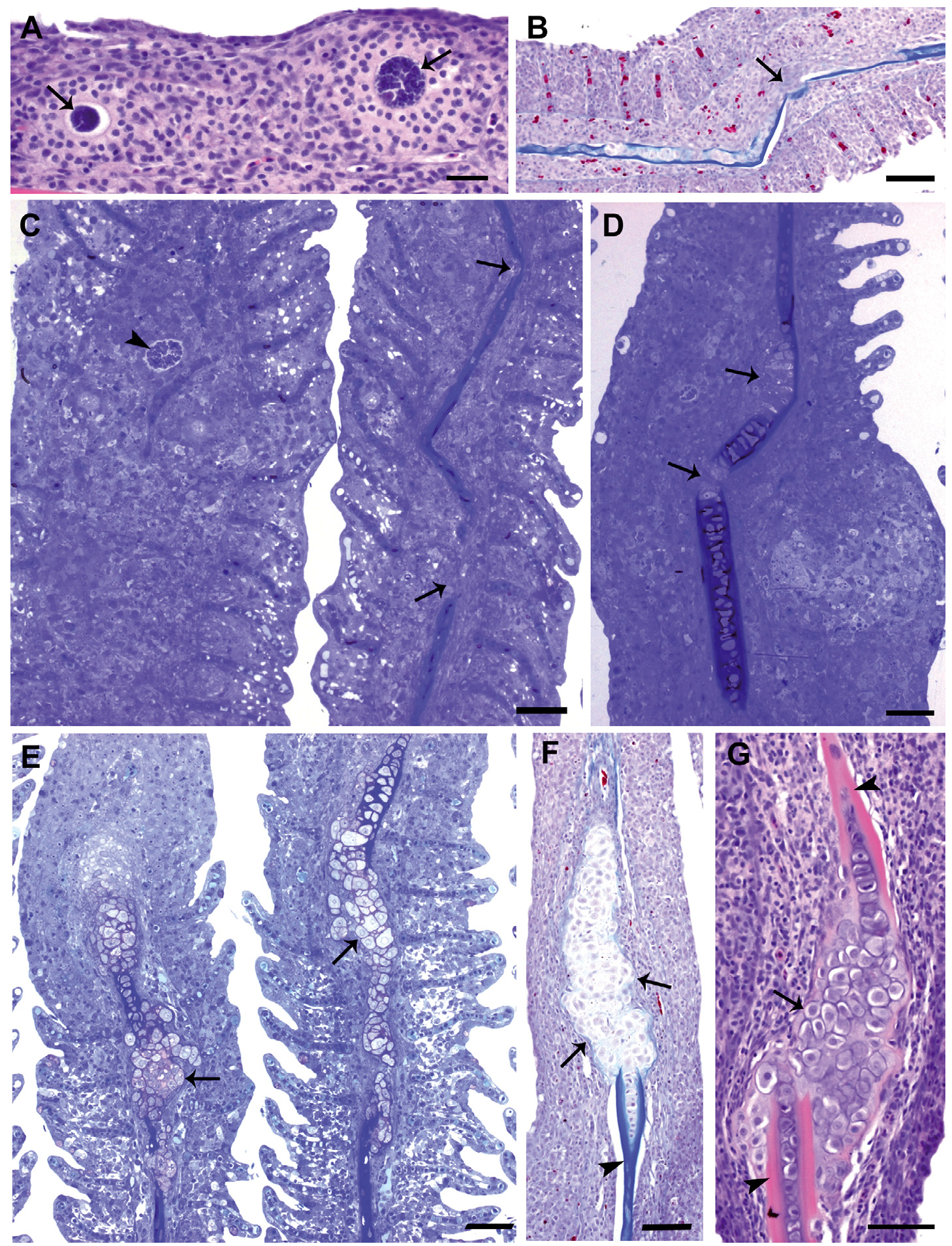

Fig. 1. Ictalurus punctatus. Light micrographs of gills affected by proliferative gill disease (PGD). (A) Trophozoites of Henneguya ictaluri (arrows) surrounded by mononuclear inflammatory cells; $5 \mu \mathrm{m}$ section stained with H\&E. (B) Gill filament with loss of collagen in areas of broken cartilage (arrow); $5 \mu \mathrm{m}$ section stained with Masson's trichrome. (C) Two gill filaments affected by PGD; the right filament has missing collagen and breaks (arrows) in the highly acellular cartilage. The left gill filament has a pronounced inflammatory infiltrate with Henneguya spp. trophozoites (arrowhead); $0.5 \mu \mathrm{m}$ section stained with toluidine blue. (D) Highly cellular form of cartilage with breaks and lost collagen (arrows) with a notable inflammatory infiltrate; $0.5 \mu \mathrm{m}$ section stained with toluidine blue. (E-G) Gill filament cartilage containing hyperplastic and hypertrophic chondrocytes (arrows). Notice areas of normal cartilage organization (arrowheads) in $(\mathrm{F}, \mathrm{G})$. (E) $0.5 \mu \mathrm{m}$ section stained with toluidine blue. (F) $5 \mu \mathrm{m}$ section stained with Masson's trichrome. (G) $5 \mu \mathrm{m}$ section stained with H\&E. Scale bars = (A) $20 \mu \mathrm{m}$, (B-G) $50 \mu \mathrm{m}$ 

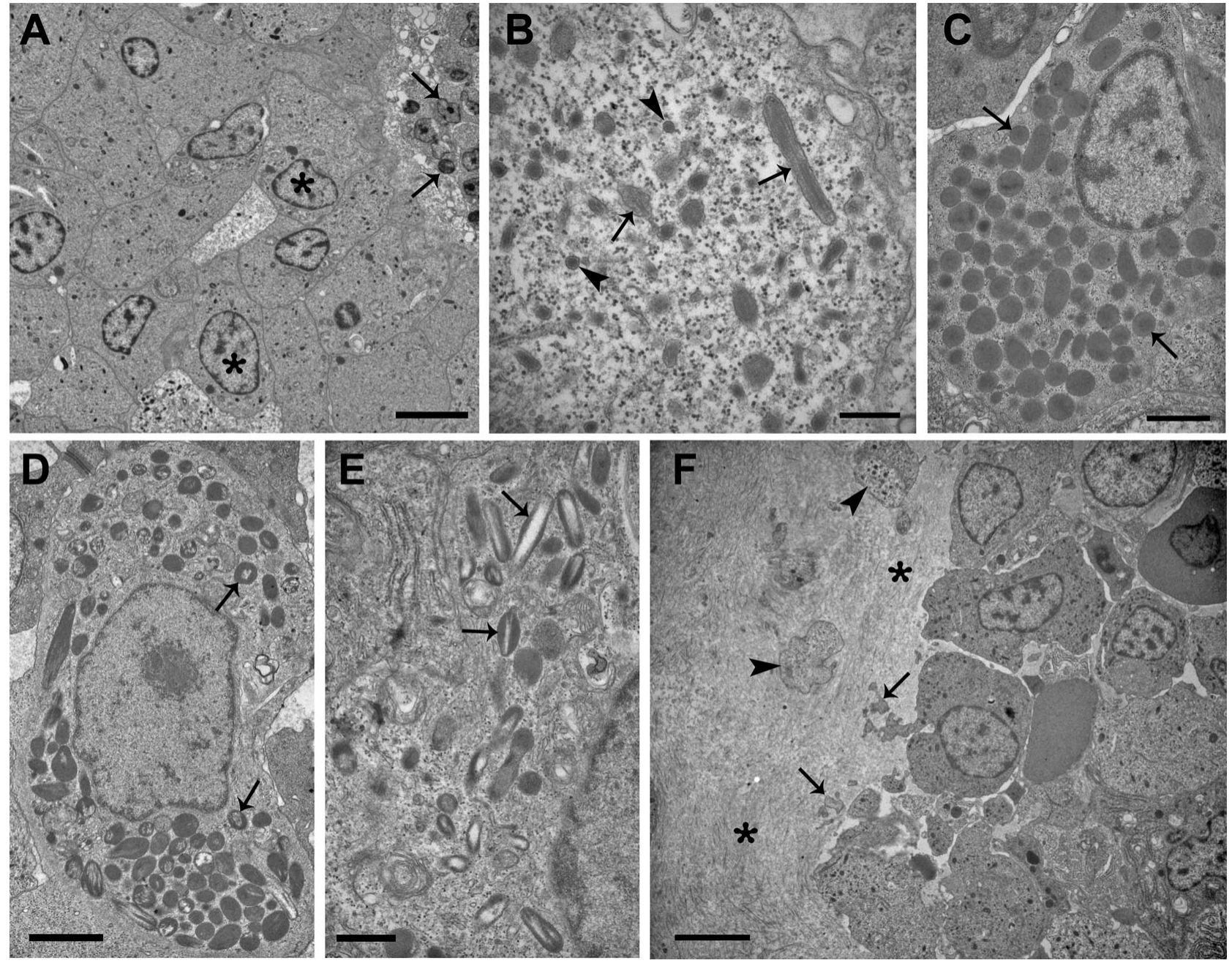

Fig. 2. Ictalurus punctatus. Transmission electron micrographs of inflammatory cells in response to proliferative gill disease (PGD). (A) Mononuclear inflammatory cells (*) directly surrounding the parasites (arrows). (B) Cytoplasmic granules of mononuclear cells from (A) include elongated granules with fibrillar material (arrows) and small pleomorphic granules (arrowheads). (C) A granulocyte with abundant intact granules (arrows). (D) A degranulating (arrows) granulocyte. (E) Central granule contents are degranulated (arrows). (F) Inflammatory response directly adjacent to the collagen layer (*) of the gill filament cartilage. Granulocytes are extending pseudopods (arrows) into the collagen $(*)$ or have infiltrated within the collagen layer (arrowheads). Scale bars $=(\mathrm{A}, \mathrm{F}) 5 \mu \mathrm{m},(\mathrm{B}) 500 \mathrm{~nm},(\mathrm{C}, \mathrm{E}) 1 \mu \mathrm{m},(\mathrm{D}) 2 \mu \mathrm{m}$

were relatively large, cuboidal, and closely apposed to each other with a thin layer of territorial matrix separating the neighboring chondrocytes. Enclosing the cuboidal chondrocytes and territorial matrix was the fibrous layer composed of collagen. The chondrocytes within the cellular cartilage contained little rough endoplasmic reticulum (RER) (Fig. 4C). In PGD-affected cartilage there was a loss of the surrounding collagen. The chondrocytes that were no longer surrounded by an obvious collagen layer were hypertrophied (Fig. 4D). The hypertrophic chondrocytes contained large amounts of RER in the cytoplasm and a primarily euchromatic nucleus, lacking the peripheral heterochromatin observed in the normal chondrocytes (Fig. 4E). The areas directly adjacent to the hypertrophic chondrocytes were largely electron lucent, instead of being surrounded by the dark territorial matrix (Fig. 4E). In some lesions, cell death was evident in the chondrocytes in which the cytoplasm was mostly devoid of organelles and the nucleus was condensed and star-shaped (Fig. 4F,G). The necrotic chondrocytes also had normal chondrocytes adjacent to them and the territorial matrix was apparent between the cells (Fig. 4F,G). Lesions with a severe inflammatory response led to the complete destruction of the filament cartilage, in which hypertrophied chondrocytes were observed freely within the inflammatory infiltrate. In these cases there was no evidence of other structural components of the cartilage (Fig. 4H). 

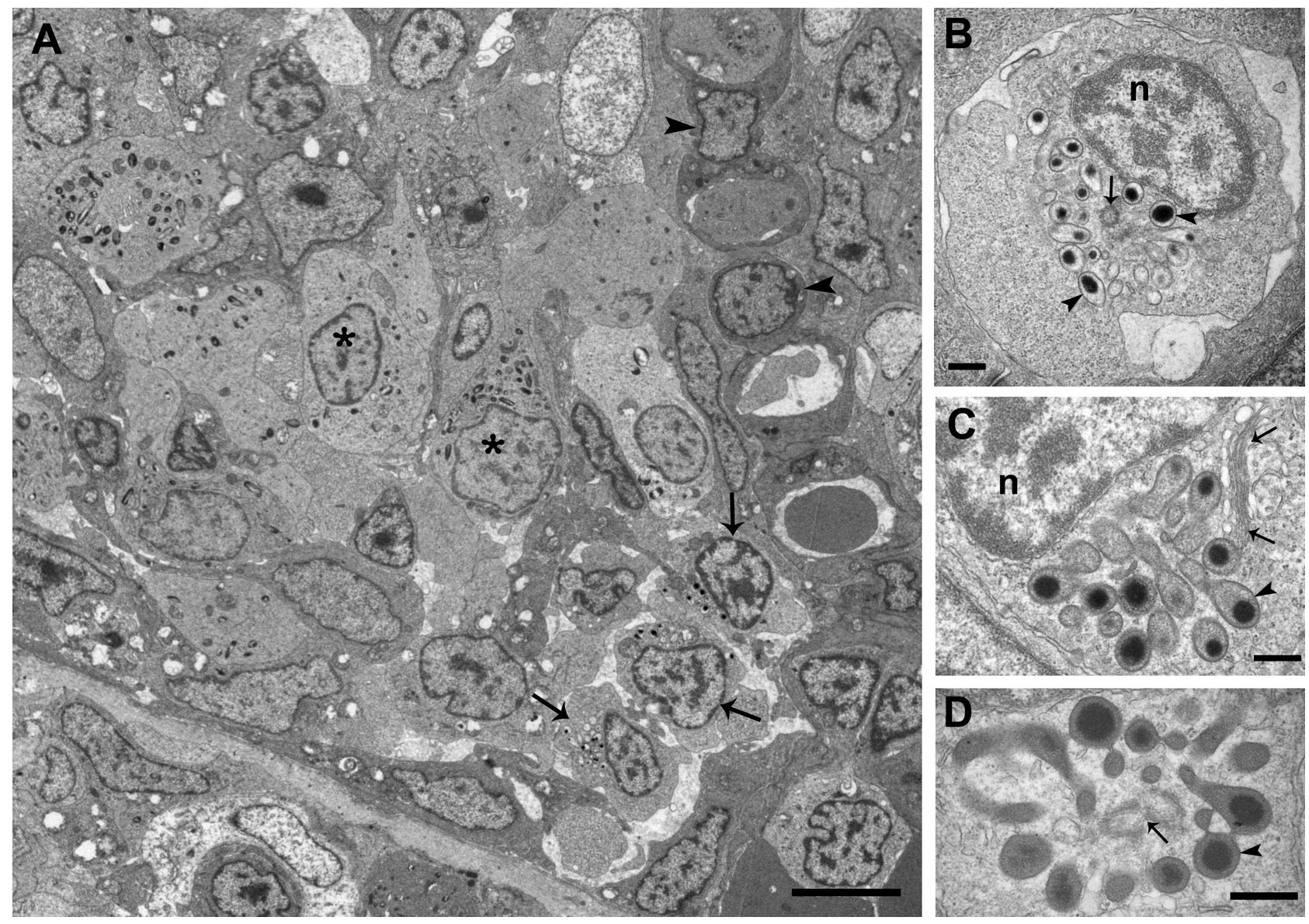

Fig. 3. Ictalurus punctatus. Transmission electron micrographs of Langerhans-like cells in gills of proliferative gill disease (PGD)affected catfish. (A) Langerhans-like cells (arrows) and degranulated granulocytes (*) within the lamellar epithelium. Arrowheads: pillar cells. (B) Langerhans-like cell containing granules (arrowheads) localized near a centrisome (arrow). n: cell nucleus. (C) Granules (arrowhead) in close proximity to the Golgi apparatus (arrows). n: cell nucleus. (D) Granules containing electrondense material surrounding dense deposits (arrowhead). Arrow: cell centrisome. Scale bars = (A) $5 \mu \mathrm{m},(\mathrm{B}-\mathrm{D}) 500 \mathrm{~nm}$

\section{DISCUSSION}

A critical component of PGD is the effect of the disease on the fibrous component, particularly collagen, of the gill filament cartilage. There was a clear correlation between collagen loss in the gill filament cartilage and breaks in the cartilage. Areas of chondrocyte proliferation and hypertrophy were also devoid of collagen. Our results suggest that the collagen is broken down and breaks develop during the early stages of disease, before evidence of a host inflammatory response, chondroplasia or the occurrence of parasites. This is further supported by Wise et al. (2008), who demonstrated that gill filament breaks occur before the histological detection of the parasite in the gills. As collagen is the major component for the structural integrity of cartilage, it is logical that its breakdown would lead to weakness in the filament cartilage, which could progress to breaks. It will be important to determine the initial cause of the collagen breakdown to better understand the pathogenesis of disease. Considering cartilage breaks occur before a notable inflammatory response, it is possible that proteases are released from early parasite stages that degrade the collagen in order to support growth of the trophozoites within the gill filament. For example Myxobolus cerebralis, a myxozoan in trout, digests and causes lysis of cartilage with serine proteases that cause degeneration of cartilage (Kelley et al. 2004). Kudoa thyrsites, a myxozoan of the muscle of fish, releases proteolytic enzymes that lead to histiolysis (Langdon 1991). The pronounced inflammatory response in PGD probably contributes to the breakdown of the gill filament cartilage during the later stages of disease. The presence of damaged cartilage occurring before a notable inflammatory response suggests that the initial breakdown of collagen is not caused by inflammation. Further research should be done to investigate the presence of 

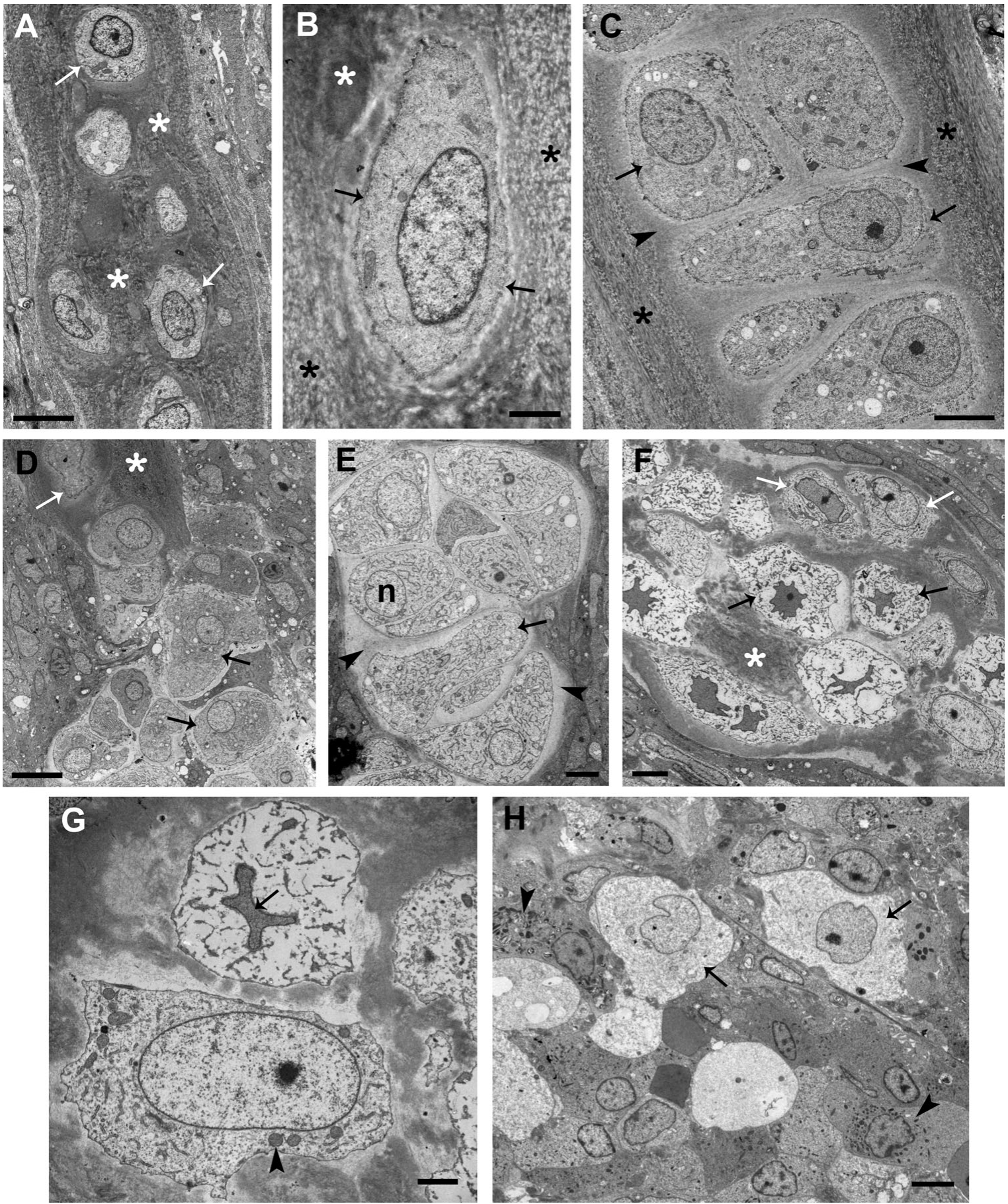

Fig. 4. Ictalurus punctatus. Transmission electron micrographs of (A-C) normal gill filament cartilage and (D-H) cartilage within proliferative gill disease (PGD)-induced lesions. (A) Mature highly acellular cartilage containing collagen (*) and chondrocytes (arrows). (B) Chondrocyte (arrows) from the type of cartilage seen in (A) surrounded by collagen (black *) and the proteoglycan component (white*). (C) Highly cellular gill filament cartilage containing chondrocytes (arrows) organized within the territorial matrix (arrowheads), and enclosed by collagen (*). (D) A normal chondrocyte (white arrow) surrounded by the collagen component $(*)$ and adjacent to hypertrophic chondrocytes (black arrows) no longer surrounded by collagen. (E) Hypertrophied chondrocytes (arrow) containing abundant rough endoplasmic reticulum (RER) and primarily euchromatic nuclei (n). Chondrocytes are surrounded by electron-lucent material (arrowheads). (F) Necrotic chondrocytes (black arrows) near normal chondrocytes (white arrows) and territorial matrix (*). (G) Necrotic chondrocyte with a star-shaped and condensed nucleus (arrow) near a relatively normal chondrocyte (arrowhead). (H) Free chondrocytes (arrows) within an inflammatory infiltrate composed of degranulated in flammatory cells (arrowheads). Scale bars $=(\mathrm{A}, \mathrm{C}, \mathrm{E}, \mathrm{F}, \mathrm{H}) 5 \mu \mathrm{m},(\mathrm{B}, \mathrm{G}) 2 \mu \mathrm{m},(\mathrm{D}) 10 \mu \mathrm{m}$ 
proteases secreted from Henneguya spp. that could lead to the breakdown of collagen during the early infection of the gills.

The present study is the first to ultrastructurally examine the host cell response in PGD-affected fish. The response directly surrounding the pathogen consists of a uniform population of cells that most closely resembled neutrophils based on the presence of elongated fibrillar granules and abundant small pleomorphic granules (Takemori et al. 1994, Pavelka \& Roth 2005). The nuclei of the catfish neutrophils were rounded, as opposed to the more common segmented nuclei seen in other vertebrate neutrophils. The rounded shape of catfish neutrophil nuclei has been previously reported by Grizzle \& Rogers (1976) and Cannon et al. (1980). The inflammatory response was most severe in the gill filament, where the filament cartilage was replaced with the inflammatory infiltrate consisting of a mixed population of cells dominated by neutrophils and other granulocytes. The granulocytes observed in the present study had abundant granules that in some cells were large and resembled mast cells, also referred to as eosinophilic granular cells, and other cells with smaller granules that more closely resembled mammalian eosinophils. In the majority of the eosinophil-like cells the central contents of their granules were degranulated. The large numbers of degranulated cells within the lesions suggest that the nature of the inflammatory response is particularly damaging to the host tissue. Ultrastructurally this strongly resembled the degranulated eosinophil-like cells observed within the inflammatory response of Atlantic salmon Salmo salar clinically affected with amoebic gill disease (Lovy et al. 2007).

The neutrophils and degranulating granulocytes observed in the present study appeared to be chemotactic towards collagen and often infiltrated into the dense collagenous layer of the gill filament cartilage. Damage done to the extracellular matrix (ECM) is known to trigger immune and inflammatory responses; for example collagen fragments from collagenase digestion are a potent stimulator for interleukin 1 secretion in human blood mononuclear cells (Pacifici et al. 1991). The ECM is a strong modulator of inflammation in gilthead seabream Sparus aurata (CastilloBriceno et al. 2010) and collagen fragments generated from the action of proteases have a high stimulatory capacity for fish phagocytes (Castillo-Briceno et al. 2009). Because the destruction of collagen is common within the gill of PGD-affected fish, the damaged ECM of these fish probably generates potent pro-inflammatory signals. The highly inflammatory nature of PGD in channel catfish is probably linked to the expression of damage-associated molecular patterns from the early damage done to the collagen within the gill. The pres- ence of neutrophils and degranulated cells that resemble eosinophils in PGD-affected catfish gills probably contributes to collagen and the cartilage damage. Human neutrophil granules are known to contain neutrophil elastase and neutrophil collagenase (also known as MMP-8), both of which can cleave native type I collagen (Kafienah et al. 1998, Khatwa et al. 2010). The MMP-8 protein is known to promote migration of neutrophils through collagen-rich matrix (Khatwa et al. 2010) and this collagenase has been demonstrated in channel catfish to have $51 \%$ nucleotide and amino acid homology to human MMP8 (Noya et al. 1999). Stimulated catfish neutrophils are also able to degrade type I collagen (Noya et al. 1999). Interestingly, the anti-inflammatory drug, dexamethasone, blocks all collagenolytic activity during acute inflammation in a rat model (Etherington et al. 1979) and according to Belem (1994), dexamethasone administration to PGD-affected catfish causes a reduction in the inflammatory response in the gills. It is possible that dexamethasone treatment in catfish reduces the inflammatory-driven degradation of collagen seen with a PGD infection. The cells that resemble degranulated eosinophils in the present study may also contribute to the destruction of collagen. Although the contents of fish eosinophil granules are largely unknown, human eosinophils contain metalloprotein, which degrades types I and III collagen (Hibbs et al. 1982).

The finding of Langerhans-like cells within inflammatory lesions is consistent with the presence of these cells in other inflammatory gill diseases, such as in microsporidial gill disease in salmonids (Lovy et al. $2006,2008)$. These cells were identified by the presence of pericentriolar granules, which have been used as a morphological criterion for the identification of Langerhans-like cells (Lovy et al. 2010). These cells were found predominantly within the inflammatory infiltrate within the fused gill lamellar epithelium and were only rarely observed in the more severe inflammatory lesions within the gill filament. The Langerhans-like cells in catfish (ictalurids), as described in this study, contain dense bodies within the granule lumen, and ultrastructurally they strongly resemble the Langerhans-like cells in cyprinid fishes (Lovy et al. 2010). The functional importance of the dense bodies within the granule lumens of cyprinids and ictalurids and their absence within similar cells of salmonids (Lovy et al. 2008) is currently unknown. An interesting finding from this study not previously reported is the variable density of the luminal material within the granules. The common presence of a Golgi apparatus, mitochondria and multivesicular bodies (Lovy et al. 2010) near the granules suggests metabolic activity in the cells. Currently the cells are believed to be anti- 
gen-presenting cells and the material within the granule lumens may represent material that was taken up and broken down, or it may be material being synthesized and packaged within the granules. Discovering the contents of the granules will be invaluable in determining their function in these cells.

PGD in catfish causes destruction of the cartilage matrix, particularly degrading the collagen that makes up the dense outer layer of the cartilage. The destruction of the cartilage matrix leads to interesting responses of the chondrocytes, including hyperplasia and hypertrophy in areas devoid of collagen (presumably cartilage regeneration). The loss of matrix probably stimulates the chondrocytes to synthesize and secrete new matrix to repair cartilage within the lesions. This is supported by the presence of hypertrophic chondrocytes in this study that contain abundant RER, probably reflecting their active state of cartilage matrix synthesis. In the present study cell death was observed in chondrocytes within affected filament cartilage, although it was difficult to determine by ultrastructure if death in these cells was caused by apoptosis or necrosis, since features were not consistent with either. These unique features of cell death may reflect a mechanism of chondrocyte death during cartilage recovery. The chondrocyte response in PGDaffected lesions is similar to the stages of development of a soft callus during bone remodeling after a bone fracture in mammals. Bone remodeling in mammals has 4 stages: inflammation, soft callus formation, hard callus formation and finally bone remodeling (Schindeler et al. 2008). Considering that fish gill cartilage does not terminally differentiate into bone, the callus would not proceed into the development of a hard callus with osteogenesis. In mammal bone remodeling, chondrocytes proliferate to fully replace the granulation tissue to form the soft callus (Schindeler et al. 2008). The chondrocytes then undergo hypertrophy followed by cell death (Ahmed et al. 2007a). The method of chondrocyte death during this process is thought be through a non-classicial pathway of apoptosis, although the exact method is controversial and has been described as chondroptosis (Roach et al. 2004), non-apoptotic cell death (Ahmed et al. 2007b) and autophagic cell death (Shapiro et al. 2005). The chondrocytes of the gill filament cartilage in the present study were hypertrophic and some had evidence of cell death, demonstrating a pattern of callus development that is similar to that observed during bone healing in mammals.

The fish examined in this study were clinically infected channel catfish, which are chronically exposed to the parasite in the pond environment; thus, various stages of infection progression were observed. For clinical disease to occur in fish, exposure to the pathogen must occur over a chronic period. When fish are exposed to the parasite on a single day and then removed from the source of the parasite, recovery from infection rapidly occurs (Wise et al. 2008). The variety of lesions described in the present study demonstrates the complex pathogenesis of this disease and demonstrates healing in the gill filament cartilage, which is completely destroyed during infection. Considering that the use of a single exposure model leads to rapid recovery without clinical disease, it would be an ideal model to study the regenerative capacity of the gill filament cartilage. Gills are able to quickly and fully regenerate during recovery from disease, although few gill disease models lead to the gill filament destruction as seen with PGD. Thus, PGD would be an ideal model to study the cellular mechanisms of cartilage regeneration and cellular responses during infection and recovery.

\section{LITERATURE CITED}

Ahmed YA, Tatarczuch L, Pagel CN, Davies HM, Mirams M, Mackie EJ (2007a) Hypertrophy and physiological death of equine chondrocytes in vitro. Equine Vet J 39:546-552

Ahmed YA, Tatarczuch L, Pagel CN, Davies HM, Mirams M, Mackie EJ (2007b) Physiological death of hypertrophic chondrocytes. Osteoarthritis Cartilage 15:575-586

Belem AMG (1994) Portals of entry of Aurantiactinomyxon ictaluri and increased infection with Aurantiactinomyxon after immunosuppression in channel catfish. PhD dissertation, Mississippi State University, Mississippi State, MS

Belem AMG, Pote LM (2001) Portals of entry and systemic localization of proliferative gill disease organisms in channel catfish Ictalurus punctatus. Dis Aquat Org 48:37-42

Bowser PR, Conroy JD (1985) Histopathology of gill lesions in channel catfish associated with Henneguya. J Wildl Dis 21:177-179

Buonocore F, Randelli E, Casani D, Guerra L and others (2008) A CD4 homologue in sea bass (Dicentrarchus labrax): molecular characterization and structural analysis. Mol Immunol 45:3168-3177

Campos-Perez JJ, Ward M, Grabowski PS, Ellis AE, Secombes CJ (2000) The gills are an important site of iNOS expression in rainbow trout Oncorhynchus mykiss after challenge with the Gram-positive pathogen Renibacterium salmoninarum. Immunology 99:153-161

Cannon SM, Mollenhauer HH, Eurell TE, Lewis DH, Cannon AM, Tompkins C (1980) An ultrastructural study of the leukocytes of the channel catfish, Ictalurus punctatus. J Morphol 164:1-23

Castillo-Briceno P, Sepulcre MP, Chaves-Pozo E, Meseguer J, Garcia-Ayala A, Mulero V (2009) Collagen regulates the activation of professional phagocytes of the teleost fish gilthead seabream. Mol Immunol 46:1409-1415

Castillo-Briceno P, Arizcun-Arizcun M, Meseguer J, Mulero V, Garcia-Ayala A (2010) Correlated expression profile of extracellular matrix-related molecules during the inflammatory response of the teleost fish gilthead seabream. Dev Comp Immunol 34:1051-1058

- Etherington DJ, Silver IA, Gibbons R (1979) An in vitro model for the study of collagen degradation during acute inflammation. Life Sci 25:1885-1891 
Griffin MJ, Wise DJ, Camus AC, Mauel MJ, Greenway TE, Pote LM (2008) A real-time polymerase chain reaction assay for the detection of the myxozoan parasite Henneguya ictaluri in channel catfish. J Vet Diagn Invest 20:559-566

Griffin MJ, Wise DJ, Camus AC, Mauel MJ, Greenway TE, Pote LM (2010) Variation in susceptibility to Henneguya ictaluri infection by two species of catfish and their hybrid cross. J Aquat Anim Health 22:21-35

Grizzle JM, Rogers WA (1976) Anatomy and histology of the channel catfish. Auburn University Experiment Station, Auburn, AL

Haugarvoll E, Bjerkas I, Nowak BF, Hordvik I, Koppang EO (2008) Identification and characterization of a novel intraepithelial lymphoid tissue in the gills of Atlantic salmon. J Anat 213:202-209

Hibbs MS, Mainardi CL, Kang AH (1982) Type-specific collagen degradation by eosinophils. Biochem J 207:621-624

Kafienah W, Buttle DJ, Burnett D, Hollander AP (1998) Cleavage of native type I collagen by human neutrophil elastase. Biochem J 330:897-902

Kelley GO, Zagmutt-Vergara FJ, Leutenegger CM, Adkison MA, Baxa DV, Hedrick RP (2004) Identification of a serine protease gene expressed by Myxobolus cerebralis during development in rainbow trout Oncorhynchus mykiss. Dis Aquat Org 59:235-248

Khatwa UA, Kleibrink BE, Shapiro SD, Subramaniam M (2010) MMP-8 promotes polymorphonuclear cell migration through collagen barriers in obliterative bronchiolitis. J Leukoc Biol 87:69-77

Langdon JS (1991) Myoliquefaction post mortem ('milky flesh') due to Kudoa thyrsites (Gilchrist) (Myxosporea: Multivalvulida) in mahi mahi, Coryphaena hippurus L. J Fish Dis 14:45-54

Lovy J, Wright GM, Speare DJ (2006) Morphological presentation of a dendritic-like cell within the gills of Chinook salmon infected with Loma salmonae. Dev Comp Immunol 30:259-263

Lovy J, Becker JA, Speare DJ, Wadowska DW, Wright GM, Powell MD (2007) Ultrastructural examination of the host cellular response in the gills of Atlantic salmon, Salmo salar, with amoebic gill disease. Vet Pathol 44:663-671

Lovy J, Wright GM, Speare DJ (2008) Comparative cellular morphology suggesting the existence of resident dendritic cells within immune organs of salmonids. Anat Rec 291: $456-462$

Lovy J, Savidant GP, Speare DJ, Wright GM (2009) Langerin/ CD207 positive dendritic-like cells in the haemopoietic tissues of salmonids. Fish Shellfish Immunol 27: 365-368

Editorial responsibility: Sven Klimpel,

Frankfurt am Main, Germany
Lovy J, Wright GM, Speare DJ, Tyml T, Dykova I (2010) Comparative ultrastructure of Langerhans-like cells in spleens of ray-finned fishes (Actinopterygii). J Morphol 271:1229-1239

MacMillan JR, Wilson C, Thiyagarajah A (1989) Experimental induction of Proliferative Gill Disease in specific-pathogenfree channel catfish. J Aquat Anim Health 1: 245-254

Noya M, Qian Y, Ainsworth AJ (1999) Molecular and functional characterization of channel catfish (Ictalurus punctatus) neutrophil collagenase. Vet Immunol Immunopathol 67:303-316

Pacifici R, Carano A, Santoro SA, Rifas L and others (1991) Bone matrix constituents stimulate interleukin-1 release from human blood mononuclear cells. J Clin Invest 87 : 221-228

Pavelka M, Roth J (2005) Functional ultrastructure: an atlas of tissue biology and pathology. Springer, Vienna

> Pote LM, Hanson LA, Shivaji R (2000) Small subunit ribosomal RNA sequences link the cause of Proliferative Gill Disease in channel catfish to Henneguya n. sp. (Myxozoa: Myxosporea). J Aquat Anim Health 12:230-240

Pote LM, Hanson LA, Khoo L (2010) Proliferative gill disease. In: American Fisheries Society-Fish Health Section (AFS-FHS) blue book: suggested procedures for the detection and identification of certain finfish and shellfish pathogens. American Fisheries Society, Bethesda, MD, Sec. 3.7

Roach HI, Aigner T, Kouri JB (2004) Chondroptosis: a variant of apoptotic cell death in chondrocytes? Apoptosis 9: 265-277

Schindeler A, McDonald MM, Bokko P, Little DG (2008) Bone remodeling during fracture repair: the cellular picture. Semin Cell Dev Biol 19:459-466

Shapiro IM, Adams CS, Freeman T, Srinivas V (2005) Fate of the hypertrophic chondrocyte: microenvironmental perspectives on apoptosis and survival in the epiphyseal growth plate. Birth Defects Res C Embryo Today 75: 330-339

- Styer EL, Harrison LR, Burtle GJ (1991) Experimental production of Proliferative Gill Disease in channel catfish exposed to a myxozoan-infected oligochaete, Dero digitata. J Aquat Anim Health 3:288-291

Takemori N, Hirai K, Onodera R, Saito N, Miyokawa N (1994) Ultrastructure of fibrillar granules in human neutrophils. Am J Hematol 47:232-234

> Wise DJ, Griffin MJ, Terhune JS, Pote LM, Khoo LH (2008) Induction and evaluation of Proliferative Gill Disease in channel catfish fingerlings. J Aquat Anim Health 20: $236-244$

Submitted: October 6, 2010; Accepted: December 14, 2010

Proofs received from author(s): March 13, 2011 